9-6-2017

\title{
Self-resolving prepontine cyst
}

Muhammad Waqas

Aga Khan University, muhammad.waqas@aku.edu

Inamullah Khan

Aga Khan University

Reehana Khawaja

Aga Khan University

Ayesha Quddusi

Aga Khan University

Ather Enam

Aga Khan University, ather.enam@aku.edu

Follow this and additional works at: https://ecommons.aku.edu/pakistan_fhs_mc_surg_neurosurg

Part of the Neurology Commons, Neurosurgery Commons, and the Surgery Commons

\section{Recommended Citation}

Muhammad Waqas, ., Khan, I., Khawaja, R., Quddusi, A., Enam, A. (2017). Self-resolving prepontine cyst. Surgical Neurology International, 8, 215.

Available at: https://ecommons.aku.edu/pakistan_fhs_mc_surg_neurosurg/93 


\title{
Case Report
}

\section{Self-resolving prepontine cyst}

\author{
Muhammad Waqas, Inamullah Khan, Reehana Khawaja, Ayesha Quddusi, Syed Ather Enam \\ Department of Surgery, Section of Neurosurgery, The Aga Khan University Hospital, Karachi, Pakistan \\ E-mail: MuhammadWaqas - shaiq_waqas@hotmail.com; Inamullah Khan - inamullah.aku.co15@gmail.com; Reehana Khawaja - rihanakhawaja@gmail.com; \\ Ayesha Quddusi - ayeshaquddusi@hotmail.com; *Syed Ather Enam - ather.enam@aku.edu \\ *Corresponding author
}

Received: 24 April 17 Accepted:06 July $17 \quad$ Published:06 September 17

\begin{abstract}
Background: Intracranial prepontine cysts are rare and include epidermoid cysts, arachnoid cysts, and neurenteric cysts. Symptomatic prepontine cysts may require surgical intervention. Reports of spontaneous resolution of cysts are rare.

Case Description: We describe the case of a young gentleman who presented with headache and fever. Magnetic resonance imaging of the brain identified a prepontine lesion with features consistent with epidermoid cyst. During admission, the patient received symptomatic management in addition to empirical antibiotic therapy and dexamethasone. The patient improved symptomatically in the next 48 hours and was discharged. Follow-up imaging at 6 months and 1 year showed significant reduction in size of the lesion.
\end{abstract}

Conclusion: For asymptomatic prepontine cysts, a close radiological and clinical follow-up may prove useful.

Key Words: Adult brain cyst, MRI brain, prepotine cyst, self-resolution

\begin{tabular}{|l|}
\hline Access this article online \\
\hline Website: \\
www.surgicalneurologyint.com \\
\hline DOI: \\
10.4103/sni.sni_160_17 \\
\hline Quick Response Code: \\
\hline
\end{tabular}

\section{INTRODUCTION}

Prepontine cystic lesions are rare. Common types of cysts reported in this area include epidermoid cysts, arachnoid cysts, and neurenteric cysts. ${ }^{[4,6,12,14]}$ Symptomatic lesions often require surgical intervention. According to our literature search, spontaneous resolution of a cyst in prepontine area has been reported once before. ${ }^{[8]}$

In this report, we describe the case of a young gentleman who presented with headache and fever. A large prepontine cyst was found on magnetic resonance imaging (MRI) with features consistent with epidermoid cyst. The possibility of neurenteric could not be excluded. Patient was treated symptomatically. Follow-up MRI at 1 year showed significant reduction in the size of the cyst.

\section{CASE REPORT}

A 4l-year-old, right-handed gentleman presented to us in the emergency room with history of severe occipital headache for 4 days. It was constant and moderate to severe in intensity. There was no association with daytime or cough. Headache was associated with several episodes of vomiting. There were no mental status changes, seizure, or complain of motor weakness in any of his limbs.

On examination, he was well oriented to time, place, and person. Signs of meningeal irritation were absent. We also did not find any cranial nerve deficit, papilledema, or long tract signs. Systemic examination was also unremarkable. He had taken symptomatic treatment

This is an open access article distributed under the terms of the Creative Commons Attribution-NonCommercial-ShareAlike 3.0 License, which allows others to remix, tweak, and build upon the work non-commercially, as long as the author is credited and the new creations are licensed under the identical terms.

For reprints contact: reprints@medknow.com

How to cite this article: Waqas M, Khan I, Khawaja R, Quddusi A, Enam SA Self-resolving prepontine cyst. Surg Neurol Int 2017;8:215.

http://surgicalneurologyint.com/Self-resolving-prepontine-cyst/ 
without much relief in his symptoms. Family history was unremarkable for any intracranial pathologies.

Considering the nature and severity of his symptoms, we obtained an MRI brain with and without contrast. MRI brain showed a midline prepontine cyst with signals identical to cerebrospinal fluid (CSF) on $\mathrm{Tl}$ and $\mathrm{T} 2$-weighted images [Figures la, 2a and 3a]. Pre-pontine cistern was effaced with significant compression on basilar artery. The cyst showed diffusion restriction. There was no hydrocephalus.

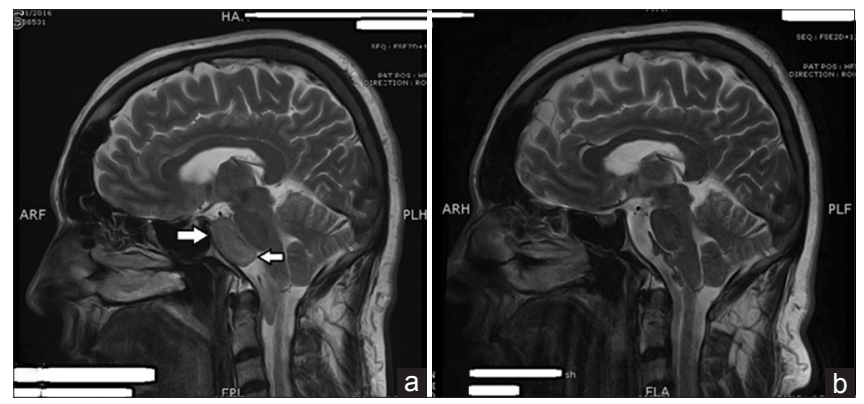

Figure I:(a)A well-defined extra-axial lesion is identified anterior to the brainstem on this sagittal view, appearing hyper intense relative to brain parenchyma on the T2 weighted image (White arrows). (b) Similar section noted one year later with reduction in mass of the cystic lesion identified in the image a
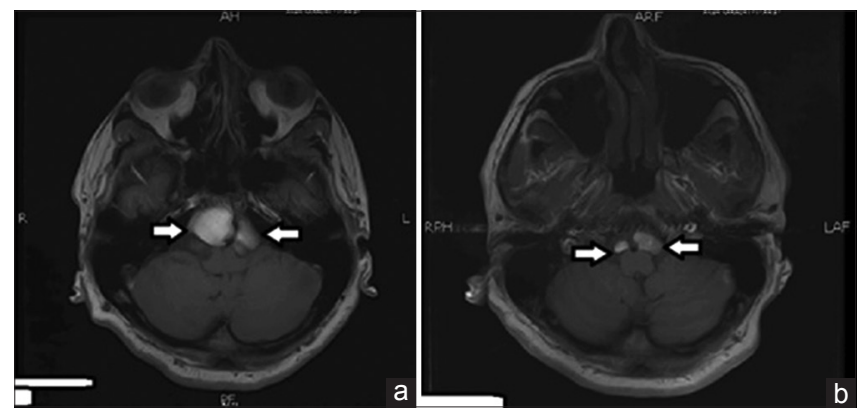

Figure 2: (a)TI weighted Brain MRI, this axial section identifies the lesion anterior to the brain stem appearing hyper intense relative to brain parenchyma (White arrows). (b) Similar section noted one year later with reduction in mass of the cystic lesion identified in the image a
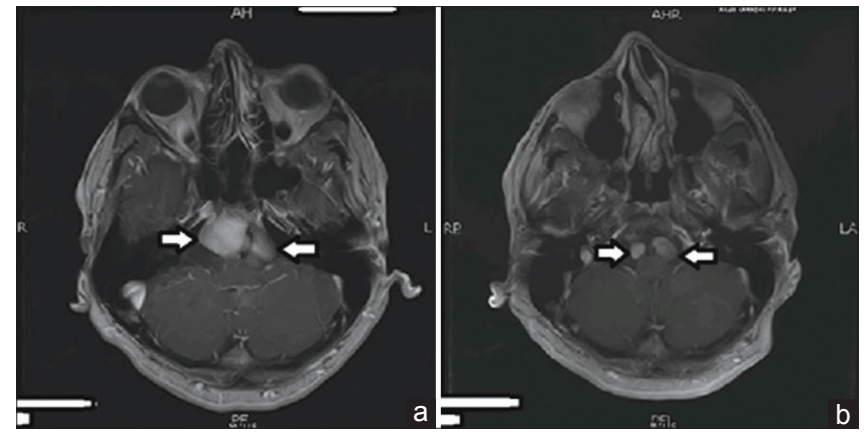

Figure 3: (a) TI weighted image with contrast Brain MRI, this axial section identifies the lesion anterior to the brain stem appearing hyper intense relative to brain parenchyma with no enhancement noticed on contrast (White arrows). (b) Similar section noted one year later with reduction in mass of the cystic lesion identified in the image a
We admitted the patient for further management. He received symptomatic management along with empirical antibiotics. Considering the possibility of chemical meningeal irritation, we also started dexamethasone for 1 week. The patient improved within the next 48 hours and was discharged with a plan for close clinical and radiological follow-up.

After discharge, the patient remained symptom free, and returned with a repeat MRI brain after 1 year. Repeat imaging showed a significant size reduction and decrease in mass effect [Figure $1 \mathrm{~b}, 2 \mathrm{~b}$ and $3 \mathrm{~b}$ ].

\section{DISCUSSION}

We have described the case of a patient with self-resolving prepontine cyst. Considering the location and radiological features, our top differentials were epidermoid and neurenteric cyst. Epidermoid cysts comprise $0.2-1.8 \%$ of primary intracranial tumors. ${ }^{[2]}$ They arise from ectodermal inclusions formed during the neural tube closure in the third to fifth weeks of gestation at the same time as the optic and octic vessels develop. This explains the frequent occurrence of epidermoid cyst in the cerebellopontine (angle 40-50\%) ) $^{[7,9,10,15]}$ and the parasellar region (10-15\%). ${ }^{[5]}$ Prepontine area is a rare location for an epidermoid cyst.

Epidermoid cyst on a computed tomography (CT) scan is a round/lobulated mass with a density resembling CSF, calcification is seen in $10 \%$ of the cases. ${ }^{[1]]}$ On MRI, hypointensity on $\mathrm{T} 1$ and hyperintensity on $\mathrm{T} 2$ is noted. Internal heterogeneity on FLAIR images this helps distinguish epidermoid cysts from arachnoid cysts. ${ }^{[3]}$

Neurenteric cysts are mostly found in the posterior fossa and are typically midline, anterior to the brainstem. ${ }^{[1,13]}$ These may arise at the time of notochordal development during the transitory existence of the neurenteric canal. The notochord and foregut fail to separate, causing primitive endodermal cells to be incorporated into the notochord leaving behind a cyst. These cause headache, cranial neuropathies, recurrent aseptic meningitis, and motor and sensory deficits. Best diagnostic tool for a neurenteric cyst is a nonenhancing round or lobulated mass in front of the medulla which appears isointense to hyperintensive on $\mathrm{Tl}$, hyperintensive on $\mathrm{T} 2$ and also hyperintense on FLAIR images.

\section{CONCLUSION}

Although spontaneous resolution of prepontine cysts is rare, in patients who are neurologically intact, symptomatic management with close clinical and radiological follow-up may prove useful.

Financial support and sponsorship Nil. 


\section{Conflicts of interest}

There are no conflicts of interest.

\section{REFERENCES}

I. Basheer N, Kasliwal MK, Suri A, Sharma MC, Arora A, Sharma BS. Lateral extradural, supratentorial neurenteric cyst. J Clin Neurosci 20 I0; 17:639-4I.

2. Bejjani GK, Wright DC, Schessel D, Sekhar LN. Endodermal cysts of the posterior fossa: Report of three cases and review of the literature. J Neurosurg 1998;89:326-35.

3. Chen CY, Wong JS, Hsieh SC, Chu JS, Chan WP. Intracranial epidermoid cyst with hemorrhage: MR imaging findings. Am J Neuroradiol 2006;27:427-9.

4. Chen CY, Wong JS, Hsieh SC, Chu JS, Chan WP. Intracranial epidermoid cyst with hemorrhage: MR imaging findings. AJNR Am J Neuroradiol 2006;27:427-9.

5. Chowdhury FH, Haque MR, Sarker MH. Intracranial epidermoid tumor; microneurosurgical management: An experience of 23 cases. Asian J Neurosurg 2013;8:21.

6. Christov C, Chretien F, Brugieres P, Djindjian M. Giant supratentorial enterogenous cyst: Report of a case, literature review, and discussion of pathogenesis. Neurosurgery 2004;54:759-63; discussion 763.
7. deSouza CE, deSouza R, da Costa S, Sperling N, Yoon TH, Abdelhamid MM, et al. Cerebellopontine angle epidermoid cysts: A report on 30 cases. J Neurol Neurosurg Psychiatry 1989;52:986-90.

8. Dodd RL, Barnes PD, Huhn SL. Spontaneous resolution of a prepontine arachnoid cyst. Case report and review of the literature. Pediatr Neurosurg 2002;37:152-7.

9. Kobata $\mathrm{H}$, Kondo $\mathrm{A}$, Iwasaki K. Cerebellopontine angle epidermoids presenting with cranial nerve hyperactive dysfunction. Skull Base 2002; $12: 178$.

10. Miyazaki S, Fukushima T, Takusagawa Y. Epidermoid presenting as trigeminal neuralgia. Neurol Med Chir 1984;24:774-8I.

II. Osborn AG, Preece MT. Intracranial cysts: Radiologic-pathologic correlation and imaging approach. Radiology 2006;239:650-64.

12. Osborn AG, Preece MT. Intracranial cysts: Radiologic-pathologic correlation and imaging approach I. Radiology 2006;239(3):650-664.

13. Preece M, Osborn A, Chin S, Smirniotopoulos J. Intracranial neurenteric cysts: Imaging and pathology spectrum. Am J Neuroradiol 2006;27:121 I-6.

14. Sampath S, Yasha TC, Shetty S, Chandramouli BA. Parasellar neurenteric cyst: Unusual site and histology: Case report. Neurosurgery 1999;44:1335-7; discussion 1337-8.

15. Zhou LF. Intracranial epidermoid tumours: Thirty-seven years of diagnosis and treatment. Br J Neurosurg 1990;4:21 I-6. 